\title{
A Financial Theory of the Insurance Firm Under Uncertainty and Regulatory Constraints*
}

\author{
by Richard D. MacMinn** and Robert C. Witt***
}

\section{An overview}

In modern microeconomic theory, the firm is typically viewed as being subject to several sources of risk in the process of its decision making. Each source of risk is likely to have an effect on the firm's behavior. The firm must determine whether the risk of entering a market is acceptable and if so how its other operations must be adjusted in response to a new source of risk. Most of the existing theory of the firm identifies only one source of risk' (price, demand, or technological uncertainty, e.g., see [2], [7], [10] and [14]) and shows that the firm makes its production decision so that expected marginal revenue equals marginal cost plus a marginal risk premium. The marginal risk premium embodies all the relevant information concerning the firm's measure of risk aversion and the riskiness of its earnings distribution, and so provides the means by which the firm may evaluate its position in a risky market.

The purpose of this paper is to construct a simplified financial theory of the risk-averse insurance firm under uncertainty and then to investigate the behavior of the firm when regulatory constraints are imposed. The rationale for the choice of this type of firm is that, unlike much of the current theory of the firm under uncertainty where only one source of risk is recognized, the insurer is subject to two independent sources of risk, i.e., the risk associated with [1] the underwriting return on its portfolio of insurance contracts and [2] the return on its portfolio of investments.

In earlier related work, Witt [16], [17] and Spellman, Witt and Rentz [15] developed financial models of the insurer which recognized these two sources of risk, but they implicitly assumed that the insurer was risk neutral and thus wanted to maximize expected profit or wealth. They basically equated expected marginal revenue and expected marginal cost to obtain their solutions because they implicitly assumed that the results of deterministic microeconomics would be basically the same under their stochastic models. However, this is

\footnotetext{
* The authors express their appreciation to the two referees who provided numerous constructive suggestions on earlier versions of this paper.

** Assistant Professor of Finance, The University of Texas at Austin. The financial support of the University Research Institute is gratefully acknowledged.

*** Joseph H. Blades Centennial Memorial Professor of Insurance and Risk Management and Chairman of the Finance Department, The University of Texas at Austin.

1 There are exceptions, e.g. see [4], [5], and [8].
} 
not always the case, as will be shown here when the insurer is risk averse. More recently, McCabe and Witt [11] developed a financial model of the insurer which also recognized the stochastic nature of the insurer's underwriting and investment acitivities. They assumed the insurer maximized expected profits subject to a probability of insolvency constraint. In essence, they assumed that the insurer was less risk averse than the insurance regulators so that the insolvency constraint was binding. Then, they determined values for their decision variables (price, the length of the claim settlement period, and the percentage of assets to be invested in risky stocks) by maximizing expected profits subject to a constraint on the probability of insolvency. Again, they equated expected marginal revenues and expected marginal costs to obtain their results. However, they showed that expected marginal cost had to include an opportunity cost for the insolvency constraint which produced a solution different from the one without the constraint because it accounted for the two major sources of risk faced by the insurer.

The model developed here is based on the assumption that a risk-averse insurer wants to maximize the expected utility of profits rather than expected profits subject to an insolvency constraint. The risk-averse individual is concerned with both tails of his payoff distribution rather than one tail as would be the case if only insolvency is considered. Of course, when insolvency is introduced the left tail of the payoff distribution has added significance because the insurer's payoff must be nonnegative, assuming no minimum capital and surplus requirements. It is shown that the insurer's utility function captures the insurer's aversion to risk through the net marginal risk premium, which is explained below and developed in the next section. This risk premium basically reflects the cost of risk which the insurer recognizes in pricing its contract.

In the model developed here, the firm's risk premium is shown to be a function of both the firm's underwriting and investment activities. The firm is shown to select its investment in risky stocks by proceeding to the point where the expected marginal investment return equals the marginal risk premium on its investment (see [1] and [12]). Similarly, the firm selects its level of underwriting activity so that the expected marginal return on underwriting equals the expected marginal losses on its insurance portfolio plus a marginal risk premium for its underwriting activity. More importantly, it is shown that given an optimal investment choice, the firm selects its level of underwriting so that its marginal revenue equals its expected marginal losses plus a net marginal risk premium (i.e., a weighted difference of the marginal risk premiums on the firm's investment and underwriting activities). This result shows that the link between the firm's investment and underwriting activities is the net marginal risk premium because it is the only term which incorporates both the investment and underwriting choices.

Three methods for regulating the behavior of the insurance firm are considered. The first regulation scheme considered places a constraint on the proportion of the firm's underwriting revenus (policyholder-supplied funds) that may be invested in risky stocks. The motivation for such an approach could be based on an expectation that it would reduce the firm's probability of insolvency. However, it is shown that the firm adjust its investment choice so that its net marginal risk premium remains the same. The result of this adaptive economic behavior is that the underwriting activity of the insurer is unaltered, as is its probability of insolvency. The only exception to this conclusion is the case in which the insurer cannot completely adjust its investment choice due to an upper limit on its investment in risky assets. Therefore, this type 
of regulation will either be ineffective or indirectly affect the insurer's risky asset investment choice.

The second regulatory scheme considered is price reguation. When the insurer's price is regulated, it is demonstrated that the riskiness of the insurer's underwriting activity increases and in response (given some reasonable restrictions on the firm's risk aversion measure and a zero probability of insolvency) the insurer increases the riskiness of its investment activity by increasing its investments in risky stocks.

The third regulatory scheme considered involves a direct regulatory constraint on the firm's investment in risky stocks. The motivation could again be to reduce the riskiness of the firm. It is shown here that if the firm is contrained to no investment in the stock market and then the constraint is relaxed, the initial effect is that the firm not only purchases risky stock but also reduces the price of its insurance contract.

\section{Optimal insurer decisions under uncertainty}

The model is framed in the context of a monopolistically competitive insurance market and competitive capital market. ${ }^{2}$ The firm is assumed to make two decisions. The first decision involves the number of homogeneous policies to sell, and this decision yields a random variable, $X_{U}$, which is the insurer's payoff from its underwriting activity. The second decision involves how to invest insurance-generated funds in a portfolio of investments in the capital markets. This decision yields a random variable, $X_{I}$, which is the insurer's payoff from its unrestricted investment activity. The two decisions are not generally separable because the funds that the firm invests in the capital markets are obtained from its underwriting operation. Hence, the firm's pricing policy and its investment activity are intertwined, and they cannot be separated without making some restrictive assumptions.

It will be assumed that firm has a downward sloping demand function, $h$, for its insurance contracts. Let $p$ denote policy price and let $a_{1}$ denote the number of policies or standard exposure units (SEU) so that $p=h\left(a_{1}\right) .^{3}$ By selling policies, the company receives $R\left(a_{1}\right)=$ $p a_{1}=h\left(a_{1}\right) a_{1}$ dollars. Suppose now that $\alpha R$ may be invested in a portfolio of risky assets and $(1-\alpha) R$ must be retained in a highly liquid risk-free form to cover some of the potential losses on the firm's underwriting portfolio (where $0<\alpha<1$ ). Assuming that the random losses of policyholders are incurred and paid at the end of the period, then these restricted underwriting funds, $(1-\alpha) R$ dollars, must be carried forward to cover these losses at the riskless return of $Z_{0}$ dollars per dollar invested in the safe asset (note that $Z_{0}$ is defined to be one plus the riskfree rate of return). Hence, the payoff on this portion of the underwriting funds, $X_{U}$, may be specified as:

$$
X_{U}=(1-\alpha) R Z_{0}-L
$$

\footnotetext{
${ }^{2}$ Arguments for using monopolistic competition as a market model to describe behavior of property and liability insurers are presented in Witt [16].

${ }^{3}$ Following McCabe and Witt [11], the number of policies is defined to be equivalent to the number of SEU's. However, the insurer is assumed to cover completely homogeneous insureds for convenience and simplicity.
} 
where $L$ is the random amount of total losses (or the aggregate pure premium), which is assumed to include a proportional expense loading for convenience and simplicity.

To characterize the random amount of total losses, $L$, let $Y$ be a non-negative random variable denoting the losses (the pure premium) associated with one standard exposure unit. Let $\psi$ be the distribution function of $Y$, let $S_{1}$ be the compact support of the distribution, and let $L\left(a_{1}, Y\right)$ denote the random total loss function for $a_{1}$ standard exposure units (the aggregate pure premium function). Than the expected total loss, $E L$, for $a_{1}$ SEU's is:

$$
E L=\int_{[0, \infty)} L\left(a_{1}, y\right) d \psi(y)
$$

where $E(\cdot)$ is the expected value operator.

It will also be assumed that the partial derivative of $L$ with respect to $a_{1}$, denoted as $L_{1}$, is positive so that the random amount of total losses increases with the number of policies written, or SEU's, as would be expected. In addition, we will assume that the partial derivative of $L_{1}$ with respect to $y$, denoted by $L_{12}$, is positive. $L_{12}$ positive yields Leland's "Principle of Increasing uncertainty" (i.e., PIU, see [8]), which says that the riskiness of the underwriting distribution increases with the number of policies written. Equivalently, the PIU implies that after correcting for the change in the mean of the underwriting distribution, due to a change in the number of policies written, the new distribution will have more weight in its tails. ${ }^{4}$

Next consider the insurer's random payoff from its unrestricted investment activity. Let $Z_{0}$ and $Z_{1}$ denote the return per dollar invested in the risk-free and risky assets, respectively, where $Z_{1}$ is one plus the risky rate of return. If the firm invests a proportion $\left(1-a_{2}\right)$ and $a_{2}$ in the risk-free and risky assets, respectively, then the investment payoff on the unrestricted underwriting revenues, $\alpha R$, is

$$
\begin{aligned}
X_{\mathrm{I}} & =\left[\left(1-a_{2}\right) Z_{0}+a_{2} Z_{1}\right] \alpha R \\
& =\left[Z_{0}+a_{2}\left(Z_{1}-Z_{0}\right)\right] \alpha R \\
& =\left(Z_{0}+a_{2} Z\right) \alpha R
\end{aligned}
$$

where $Z \equiv Z_{1}-Z_{0}$ is the net rate of return on the risky asset, and $\alpha R$ is the maximum amount of underwriting revenue or policyholder supplied funds that can be invested in risky assets. Let $\phi$ be the distribution function for $Z$ and let $S_{2}$ be the support of the distribution. Then the expected excess return on the risky asset is

$$
E Z=\int_{(-\infty, \infty)} z d \Phi(z)
$$

\footnotetext{
${ }^{4}$ This is in the Rothschild-Stiglitz, [13], sense and so, after correcting for the change in the mean of the underwriting distribution, the new distribution is riskier, or equivalently, is a mean preserving spread of the original distribution. For a proof of this assertion see proposition two in [10].
} 
Finally, the insurer's total income from its investment and underwriting activities is

$$
\begin{aligned}
X & =X_{\mathrm{U}}+X_{I} \\
& =(1-\alpha) R Z_{0}-L+\alpha R Z_{0}+a_{2} \alpha R Z \\
& =R Z_{0}-L+a_{2} \alpha R Z .
\end{aligned}
$$

If $U$ and $I$ are defined as $U=R Z_{0}-L$ and $I=a_{2} \alpha R Z$, then $U$ could be viewed as an interest-adjusted measure of underwriting income, and $I$ would be the net investment income on policyholder supplied funds in excess of the risk-free return. In practice, statutory accounting principles define underwriting income as $R-L$, which means the time value of policyholder supplied funds is ignored in this insurance accounting definition. In contrast, the economic definition of underwriting income, $U$, used here recognizes the time value of these funds and is therefore larger than the accounting value that would be reported in practice. These special economic definitions will be used later in the paper rather than statutory accounting definitions.

Having specified the insurer's payoff $X=U+I$, we need to consider the insurer's probability of solvency. We assume that the random variables $Y$ and $Z$ are independent so that $L$ and $Z$ are independent. Of course, it also follows that $U$ and $I$ are independent. One or both of the random variables $U$ and $I$ and may take on negative values and so the realized payoff may be $x<0$ in which case the firm is insolvent. ${ }^{5}$ Let $S(a)$ denote the solvency set. Then $S(a)=\left\{(y, z) \mid U+I \geq 0 \quad 1\right.$ For fixed $a=\left(a_{1}, a_{2}\right)$ the following equation implicitly defines the pairs $(y, z)$ on the boundary of $S(a)$ :

$$
R\left(a_{1}\right) Z_{0}-L\left(a_{1}, y\right)+a_{2} \alpha R\left(a_{1}\right) z=0 .
$$

Let $T(y, z, a)$ be defined by the LHS of the above equation. Note that $T_{1}<0$ and so by the Implicit function Theorem there exists a function $t: \mathbb{R}^{2} \rightarrow \mathbb{R}$ such that $T(t(z, a), z, a)=0$ and $t_{1}(z, a)=-T_{2} / T_{1}$. It may be noted that $t_{1}>0$, since $T_{2}>0$. Also note that $z$ must be greater than or equal to $-Z_{0} / a_{2} \alpha$ if $a_{2}>0$. Now the solvency set $S(a)$ may be specified as $\left\{(y, z) \mid z \geq-Z_{0} / a_{2} \alpha\right.$ and $y \leq t(z, a)\}$. For the case in with $L\left(a_{1} y\right)=a_{1} y$ we obtain $t(z, a)=\left[R\left(a_{1}\right) Z_{0}+a_{2} \alpha R\left(a_{1}\right) z\right] / a_{1}$ $=h\left(a_{1}\right) Z_{0}+a_{2} \alpha h\left(a_{1}\right) z$. In this case we may note that $t(0, a)=h\left(a_{1}\right) Z_{0}$ and $t_{1}=a_{2} \alpha h\left(a_{1}\right)$. The solvency set for the case $L\left(a_{1}, y\right)=a_{1} y$ is shown in Figure 1 .

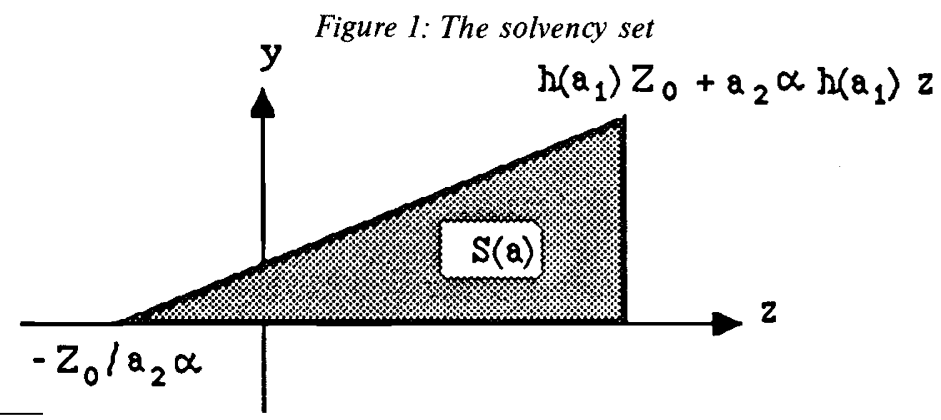

\footnotetext{
${ }^{5}$ For simplicity, we are assuming no minimum capital or surplus requirement. We could set some minimum such as $k$ dollars; then $x<-k$ would yield insolvency. The introduction of a positive constant $k$ would not affect the character of our results.
} 
The probability of solvency is $P(X \geq 0)$ where

$$
\begin{aligned}
P(X & \geq 0)=P(U+I \geq 0) \\
& =\int_{(s(a), \infty)} \int_{(0, t(z, a))} d \psi(y) d \Phi(z) \\
& =\int_{(s(a), \infty)} \psi(t(z, a) d \Phi(z),
\end{aligned}
$$

where $s(a)=-Z_{0} / a_{2} \alpha$. As one should expect and as this expression shows, the probability of solvency (or insolvency) depends on both the firm's underwriting and investment policies. Now consider how the probability of solvency changes as the firm changes the number of insurance policies it supplies to the market. The change in the solvency set is shown in Figure 2 . This figure makes it apparent that the probability of solvency eventually decreases as the number of policies increases. ${ }^{6}$ This may be seen by noting that if the number of policies sold increases from $a_{1}{ }^{0}$ to $a_{1}{ }^{1}$, as shown in Figure 2, then the size of the solvency set decreases. Differentiating the probability of solvency partially with respect to $a_{1}$ yields

Figure 2

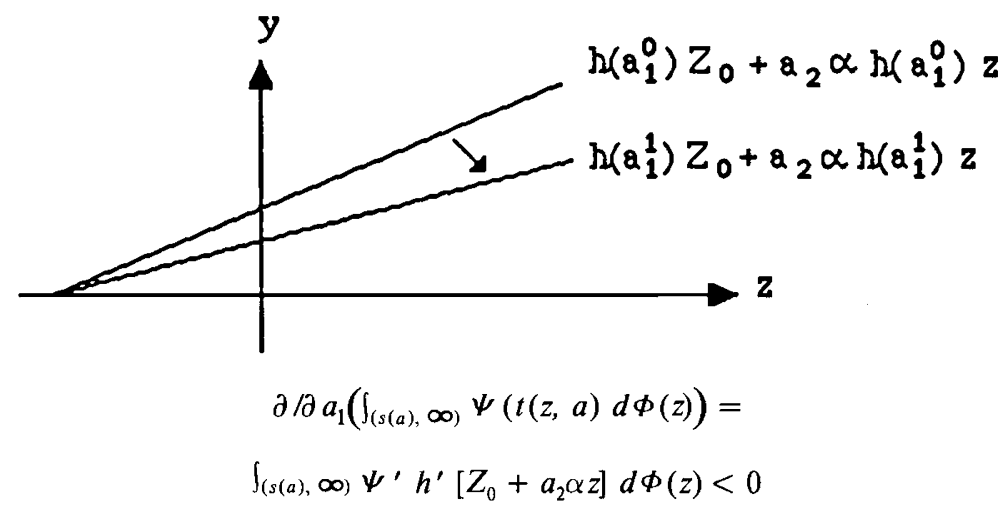

since $\psi^{\prime}>0, h^{\prime}<0$, and $z \geq-Z_{0} / a_{2} \alpha$ yields $Z_{0}+a_{2} \alpha z \geq 0$. Therefore the probability of solvency decreases, or equivalently, the probability of insolvency increases in $a_{1}$ once the solvency set is a subset of the support of the joint distribution, i.e., $S(a) \cap S_{1} \times S_{2} \subset S_{1} \times S_{2}$.

Next, consider how a change in the firm's investment policy affects the probability of solvency. Differentiating the probability of solvency partially with respect to $a_{2}$ yields

$$
\begin{gathered}
\partial / \partial a_{2}\left(\int_{(s(a), \infty)} \psi(t(z, a) d \Phi(z))=\right. \\
-\psi(0) Z_{0} /\left(a_{2}\right)^{2} \alpha+\int_{(s(a), \infty)} \psi^{\prime} h \alpha z d \Phi(z)= \\
h \alpha \int_{(s(a), \infty)} \psi^{\prime}(t(z, a)) z d \Phi(z)
\end{gathered}
$$

${ }^{6}$ It should be noted that the Principle of Increasing Uncertainty provides this result, i.e., as the number of policies increases, the loss distribution gains more weight in its tails and so the probability of insolvency increases, or equivalently, the probability of solvency decreases. 
Notice that if $a_{2}=0$ then this partial derivative is simply $\psi^{\prime}\left(h\left(a_{1}\right) Z_{0}\right) E Z$ and this terms is positive if and only if the expected rate of return on the risky asset is greater than the rate of return on the riskless asset, i.e., $E Z>0$. Therefore the probability of solvency initially increases with $a_{2}$. The change in the solvency set is shown in Figure 3. As one can observe, it is not apparent that the probability of solvency increases with $a_{2}$ for all values of $a_{2}$. As $a_{2}$ increases from $a_{2}{ }^{0}$ to $a_{2}{ }^{1}$ the boundary line of the solvency set pivots about the intercept, as shown in Figure 3. There are special cases in which it is apparent that the probability of solvency increases for all $a_{2}$. Note that if $\psi^{\prime}(y)$ is a uniform density then the

Figure 3

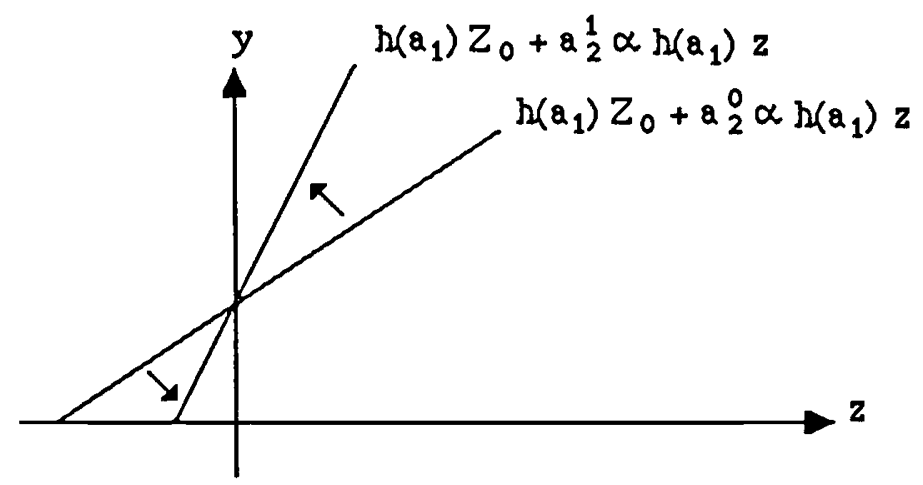

probability of solvency increases. Of course, the more likely case is the one in which $\psi^{\prime}(y)$ is eventually decreasing and so we expect the probability of solvency to eventually decrease with $a_{2}$.

Now consider the objective of the insurance firm. If the firm is insolvent then its payoff is zero while if the firm is solvent its payoff is $X=U+I$. Hence, the firm's payoff is max $\{0, X\}$ and the firm selects an underwriting and investment policy $a=\left(a_{1}, a_{2}\right)$ to maximize its expected utility. Let the insurer's expected utility function be $F\left(a_{1}, a_{2}\right)$ where

$$
F\left(a_{1}, a_{2}\right)=E u(\max \{0, X\})=\int_{(-\infty, \infty)} \int_{(0, \infty)} u(\max \{0, X\}) d \psi(y) d \Phi(z)
$$

where $u$ denotes the insurer's increasing concave utility function; for simplicity, we will also assume that $u(0)=0$. Equivalently, letting $S(a)$ denote the solvency set, the expected utility may be expressed as

$$
F\left(a_{1}, a_{2}\right)=\iint_{\mathrm{S}(a)} u(X) d \psi(y) d \Phi(z)=\int_{(s(a), \infty)} \int_{(0, t(z, a))} u(X) d \psi(y) d \Phi(z) .
$$

In order to determine the first order conditions we use Leibniz's rule as follows:

$$
\begin{gathered}
\partial \partial a_{1}\left(\int_{(s(a), \infty)} \int_{(0, t(z, a))} u(X) d \psi(y) d \Phi(z)\right)= \\
\partial t(z, a) / \partial a_{1} \int_{(s(a), \infty)} u(0) \psi^{\prime}(0) d \Phi(z)+ \\
\int_{(s(a), \infty)} \int_{(0, t(z, a))} u^{\prime}(X)\left[R^{\prime} Z_{0}-L_{1}+a_{2} \alpha R^{\prime} z\right] d \psi(y) d \Phi(z)
\end{gathered}
$$


The first expression on the RHS of the above equation is zero since $X$ evaluated at $t(z, a)$ is zero and $u(0)=0$. Therefore the first order condition for $a_{1}$ is

$$
F_{1}\left(a_{1}, a_{2}\right)=\int_{(s(a), \infty)} \int_{(0, t(z, a))} u^{\prime}(X)\left[R^{\prime} Z_{0}-L_{1}+a_{2} \alpha R^{\prime} z\right] d \psi d \Phi=0 .
$$

The same method is applied to determine $F_{2}$ and we find that the first order condition for $a_{2}$ is

$$
F_{2}\left(a_{1}, a_{2}\right)=\int_{(s(a), \infty)} \int_{(0, t(z, a))} u^{\prime}(X) \alpha R z d \psi d \Phi=0 .
$$

Using (2), note that (1) may be reduced to

$$
\int_{(s(a), \infty)} \int_{(0, t(z, a))} u^{\prime}(X)\left[R^{\prime} Z_{0}-L_{1}\right] d \psi d \Phi=0 .
$$

Alternatively, this condition may be expressed as

$$
R^{\prime}=\int_{(s(a), \infty)} \int_{(0, t(z, a))} u^{\prime}(X) \mathrm{L}_{1} d \psi d \Phi / Z_{0} \int_{(s(a), \infty)} \int_{(0, t(z, a))} u^{\prime}(X) d \psi d \Phi
$$

where the LHS is the marginal revenue and the RHS is the present value of the marginal cash equivalent of the loss. Yet another representation which is useful is

$$
R^{\prime}=\left(1 / Z_{0}\right)\left[E\left\{L_{1} \mid X \geq 0\right\}+\Delta\right],
$$

where $\Delta$ is the net marginal risk premium and is defined as

$$
\Delta=\operatorname{Cov}\left\{\left(u^{\prime}(X), L_{1}\right) \mid X \geq 0\right\} / E\left\{u^{\prime}(X) \mid X \geq 0\right\}
$$

This results shows that the insurance firm will select its underwriting and investment levels so that its marginal underwriting revenus, $R^{\prime}$, equals the present value of its expected marginal losses, given solvency, plus a net marginal risk premium, as shown in Figure 4.

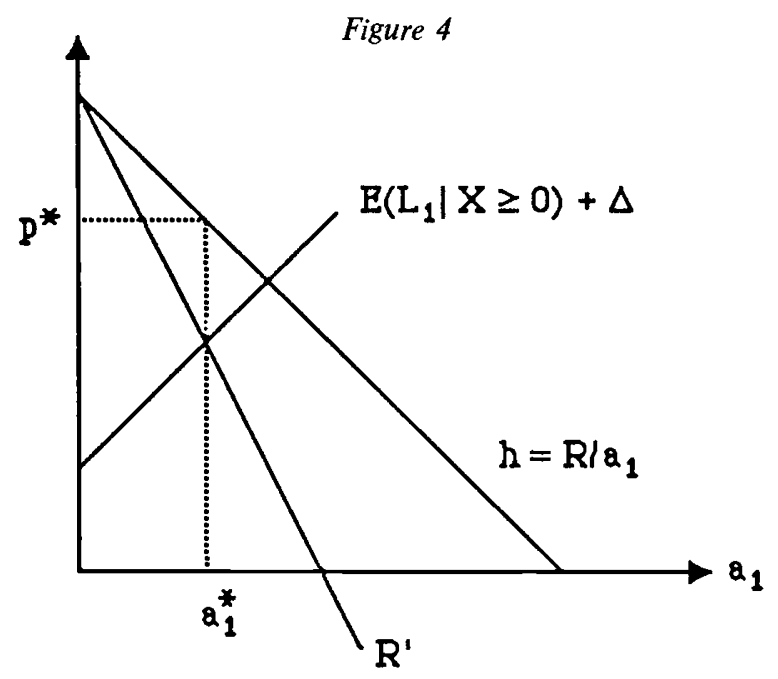


To see why $\Delta$, the second term on the RHS of (3), may be interpreted as a net marginal risk premium, let $\pi$ denote the risk premium. Recall that $\pi$ is implicitly defined by the relation $u(E \max \{0, X\}-\pi)=E u(\max \{0, X\})$ and it is a function of both decision variables $a_{1}$ and $a_{2}$. The first order conditions in (1) and (2) may also be derived by taking partial derivatives of $u(E \max \{0, X\}-\pi)$ with respects to $a_{1}$ and $a_{2}$ and then the derivatives may be equivalently expressed as

$$
\int_{(s(a), \infty)} \int_{(0, t(z, a))}\left[R^{\prime} Z_{0}-L_{1}+a_{2} \alpha R^{\prime} z\right] d \psi d \phi=\pi_{1}
$$

and

$$
\left.\int_{(s(a), \infty)} \int_{(0, t(z, a))} \alpha R z\right] d \psi d \Phi=\pi_{2}
$$

where $\pi_{1}$ and $\pi_{2}$ are the marginal risk premiums, i.e., $\pi_{j}$ is the rate of change of $\pi$ with respect to $a_{\mathrm{j}}, j=1,2$. From (1) and (2), it follows that

$$
\begin{aligned}
\pi_{1}= & -\operatorname{Cov}\left(u^{\prime}(X),\left(R^{\prime} Z_{0}-L_{1}+a_{2} \alpha R^{\prime} Z\right) \mid X \geq 0\right) P(X \geq 0) / E u^{\prime}(X \mid X \geq 0) \\
& =\left[\operatorname{Cov}\left(u^{\prime}(X) . L_{1} \mid X \geq 0\right) P(X \geq 0) / E u^{\prime}(X \mid X \geq 0)\right] \\
& -a_{2} \alpha R^{\prime}\left[\operatorname{Cov}\left(u^{\prime}(X), Z \mid X \geq 0\right) P(X \geq 0) / E u^{\prime}(X \mid X \geq 0)\right]
\end{aligned}
$$

and

$$
\pi_{2}=-\alpha R \operatorname{Cov}\left(u^{\prime}(X), Z \mid X \geq 0\right) P(X \geq 0) / E u^{\prime}(X \mid X \geq 0)
$$

Therefore, using (5), condition (4) may be rewritten as $R^{\prime}=\left(1 / Z_{0}\right)\left[E\left(L_{1} \mid X \geq 0\right)+\Delta\right]$; note that this is how it is expressed in (3). Therefore, it can be seen that $\Delta=\left[\pi_{1}-a_{2}\left(R^{\prime} / R\right) \pi_{2}\right] /$ $P(X \geq 0)$ and this explains why this term in equation (3) is referred to as a net marginal risk premium.

It should also be observed that the net marginal risk premium, $\Delta$, is positive. Recall that by definition $\Delta=\operatorname{Cov}\left(u^{\prime}(X), L_{1} \mid X \geq 0\right) / E u^{\prime}(X \geq 0)$ and so this net marginal risk premium is positive if and only if the conditional covariance term is positive. Of course, this is clearly the case. To see this note that $L_{1}$ and $Y$ are positively related by the PIU, $Y$ and $Z$ are independent and so $L_{1}$ and $I$ are also independent, and $Y$ and $U$ are negatively related. Therefore, given risk aversion (i.e., $u^{\prime \prime}<0$ ), it follows that $u^{\prime}(X)$ and $L_{1}$ are positively related, or equivalently, that the covariance is positive. It may also be observed at this point that the risk-averse firm will sell fewer insurance contracts and charge a higher price than the risk-neutral firm because $\Delta>0$.

Several observations can be made at this point. First, it may be noted that if $a_{2}=0$ then all underwriting revenue is invested in the safe asset. Hence, the condition for selecting the number policies to write, or equivalently the policy price, is like condition (3), with the provision that the firm's payoff is $R Z_{0}-L$. The firm will select a positive $a_{2}$ if $F_{2}\left(a_{1}, 0\right)>0$. In this case $t_{1}(z, a)=0$ and we may simply let $t$ be the real number such that $R\left(a_{1}\right) Z_{0}-L\left(a_{1}, t\right)=0$.

$$
\begin{aligned}
F_{2}\left(a_{1}, 0\right) & =\alpha R \int_{(-\infty, \infty)} \int_{(0, t)} u^{\prime}\left(R Z_{0}-L\right) z d \Psi d \phi \\
& =\alpha R E\left\{u^{\prime}\left(R Z_{0}-L\right) \mid Y \leq t\right\} P(Y \leq t) E Z \\
& >0
\end{aligned}
$$

if and only if $E Z>0$. 
Second, there is one special case of the model involving constant absolute risk aversion that should be noted because, if the probability of insolvency is zero then it allows the firm to separate its underwriting and investment policies. Let $r_{u}=-\left(u^{\prime \prime} / u^{\prime}\right)$ denote the firm's measure of absolute risk aversion. If this measure of absolute risk aversion is a constant, then the underwriting policy of the firm does not depend on its investment policy. In this case, the utility function takes the exponential form $u(X)=1-e^{-\mathrm{rx}}$ (i.e., this form is used to be consistent with our assumption $u(0)=0$ ), so that $r_{u}(X)=r$ for all possible values of total income, $X$, on the support of the distribution. The separation property may be seen by noting that the insurer's net marginal risk premium is unaffected by its choice of $a_{2}$. To see this, let $U=R Z_{0}-L$ and $X=$ $U+I$, where $I=a_{2} \alpha R$ Z.If $a_{2}>0$, then the net marginal risk premium can be specified as follows:

$$
\begin{gathered}
\operatorname{Cov}\left(u^{\prime}(X), L_{1}\right) / E u^{\prime}(X)= \\
\int_{(0, \infty)} \int_{(-\infty \infty)} u^{\prime}(U+I)\left[L_{1}-E L_{1}\right] d \Phi d \psi / \int_{(0, \infty)} \int_{(-\infty \infty)} u^{\prime}(U+I) d \Phi d \psi= \\
\int_{(0, \infty)} \int_{(-\infty \infty)} r e^{-r(U+1)}\left[L_{1}-E L_{1}\right] d \Phi d \psi / \int_{(0, \infty)} \int_{(-\infty \infty)} r e^{-r(U+1)} d \Phi d \psi= \\
\int_{(0, \infty)} e^{r U}\left[L_{1}-E L_{1}\right] d \psi / \int_{(0, \infty)} e^{-r U} \psi= \\
\operatorname{Cov}\left(u^{\prime}(U), L_{1}\right) / E u^{\prime}(U) .
\end{gathered}
$$

Hence, it can be seen that the marginal risk premium in (3) is unaffected by the firm's choice of $a_{2}$, and, therefore, separation of underwriting and investment policies holds given constant absolute risk aversion and a zero probability of insolvency. ${ }^{7}$ Note that the constant absolute risk case includes risk neutrality as a special case, i.e., let $r=0$ and note that the equality above is trivially true. Therefore, if the insurer is risk neutral, the separation result holds. This might be the case for a publicly-held insurer with many stockholders who hold diversified investment portfolios. Management might merely want to maximize expected profit in this case. ${ }^{8}$

\section{Regulation of insurer behavior}

In this section, several possible ways to regulate the behavior of the insurance firm are considered. The regulation schemes include (1) constraining the proportion of the firm's underwriting revenue or policyholder-supplied funds that may be invested in the stock mar-

${ }^{7}$ Freifelder [6] has developed a theoretical insurance ratemaking model based on an assumption of constant absolute risk aversion.

${ }^{8} \mathrm{~A}$ similar argument might be made for a large mutual insurance company where the policiholders and "shareholders" (owners) are the same individuals. Of course, if policyholders in a mutual company do not hold well diversified investment portfolios, this argument would not hold. Some empirical research on investment portfolios of mutual policyholders might offer some interesting insights. The objective of a mutual insurance company is not entirely clear, but is frequently alleged to be the minimization of the cost of insurance. However, it should be emphasized that the notion of cost minimization does not completely specify the insurer's objective function. For example, the expected-profit maximizing firm will minimize cost at the output level selected. Alternatively, the firm could minimize cost subject to satisfying demand. Hence, it can be seen that cost minimization partially characterizes both objectives, but the two objectives generally lead to different output decisions. 
ket, (2) directly regulating the price of the insurer's policy, and (3) regulating the proportion of the insurer's total investments that may be put at risk in the stock market. In each case, the effect of government regulation on the insurer's optimal underwriting and investment policy will be assessed.

\subsection{Investment regulation of policyholder supplied funds}

First, suppose that the government regulates the proportion of the insurer's underwriting revenue or policyholder supplied funds that may be invested in the stock market. In this scheme, $\alpha$ is treated as the government's policy parameter. Recall that the random amount for restricted income has been defined as:

$$
X_{\mathrm{U}}=(1-\alpha) R Z_{0}-L
$$

where $L$ is the random total loss, which is paid at the end of the policy period and is an increasing function of the number of SEU's or policies written. It follows that any decrease in $\alpha$ will increase the firm's restricted underwriting income, which is invested in riskless assets, and decrease the probability of a loss on this portion of underwriting revenue; i.e., the $P\left(X_{U}<0\right)$ will decrease as $\alpha$ increases. Alternatively, $\alpha$ could be regulated so that $E X_{U}=(1-\alpha) R Z_{0}-E L=0$. Of course, if $\alpha$ is regulated, the total revenue of the firm must be considered. Recall that $X=X_{U}+X_{I}=U+I$, where $U=R Z_{0}-L$ and $I=a_{2} \alpha R Z$. Initially, it might seem that regulating $\alpha$ may alter the mean and riskiness of the insurer's gains or losses on its stock market investment. However, the insurer can compensate for any changes in $\alpha$ by changing its investment policy by varying $a_{2}$. In fact, it can be shown that it is optimal for the insurer to compensate for any change in $\alpha$ by changing its investment in the stock market so that $a_{2} \alpha=k$, where $k$ is a constant. To see this simply recall that in first order condition (2) yields

$$
\int_{(s(a), \infty)} \int_{(0, t(z, a))} u^{\prime}(X) z d \Phi d \psi=0
$$

for $\alpha R$ positive. Since the firm's payoff is $X=R Z_{0}-L+a_{2} \alpha R Z$, by selecting an optimal $a_{2}$ the firm is selecting a preferred payoff distribution and so when $\alpha$ changes the firm may maintain that preferred payoff distribution by selecting another $a_{2}$ so that $a_{2} \alpha$ is unchanged. The only exception to this result is the case in which $\alpha$ becomes so small that the upper bound on $a_{2}$, i.e., $a_{2} \leq 1$, cannot be satisfied. However, the $\alpha$ which makes this constraint binding simply provides an indirect means of regulating the risky investment decision of the firm. Direct regulation of $a_{2}$ is considered subsequently. Note that when the constraint $a_{2} \leq 1$ is not binding it also follows that the insurer will not change its price or the number of policies it sells because the riskiness of its payoff distribution is unaltered. Equivalently, when the firm changes $a_{2}$ in response to a change in $\alpha$, so that $a_{2} \alpha=k$, the distribution of $X$ remains the same and so the net marginal risk premium remains the same. Therefore it must follow that the optimal number of policies remains the same. It may be equivalently observed that the solvency set remains unchanged. Therefore, in all but the exceptional case where $a_{2} \leq 1$ is binding, there is no economic justification for this type of regulation. 


\subsection{Price regulation}

Price regulation can now be examined. Suppose the price of the policy is regulated at $p^{r}$ so that the regulated revenue function for the insurer is

$$
R^{\prime}\left(a_{1}\right)=p^{\prime} a_{1} \text {, for } a_{1} \leq a_{1}^{\prime},
$$

and $R^{\prime}\left(a_{1}\right)=R\left(a_{1}\right)$ otherwise. Then marginal revenue is $p^{\prime}$ for $a_{1} \leq a_{1}^{\prime}$ and $R^{\prime}$ otherwise, as shown in Figure 5. Recall that marginal underwriting revenue can be defined as $R^{\prime}=$ $h[1-1 / \mathcal{E}]$, where

$$
\mathcal{E}=-\left(d a_{1} / a_{1}\right) /(d p / p)=-h / h^{\prime} a_{1}
$$

is the elasticity of demand. Therefore $R^{\prime}$ is positive or negative as $\mathcal{E}$ is greater or less than one.

To determine the effect of price regulation on the insurer's investment policy, assume that the insurer finds $a_{1}^{r}$ optimal given $p^{r}$. Then for a sufficiently small change in $p^{r}$, the insurer will select an optimal $a_{2}$ so that

\section{Figure 5}

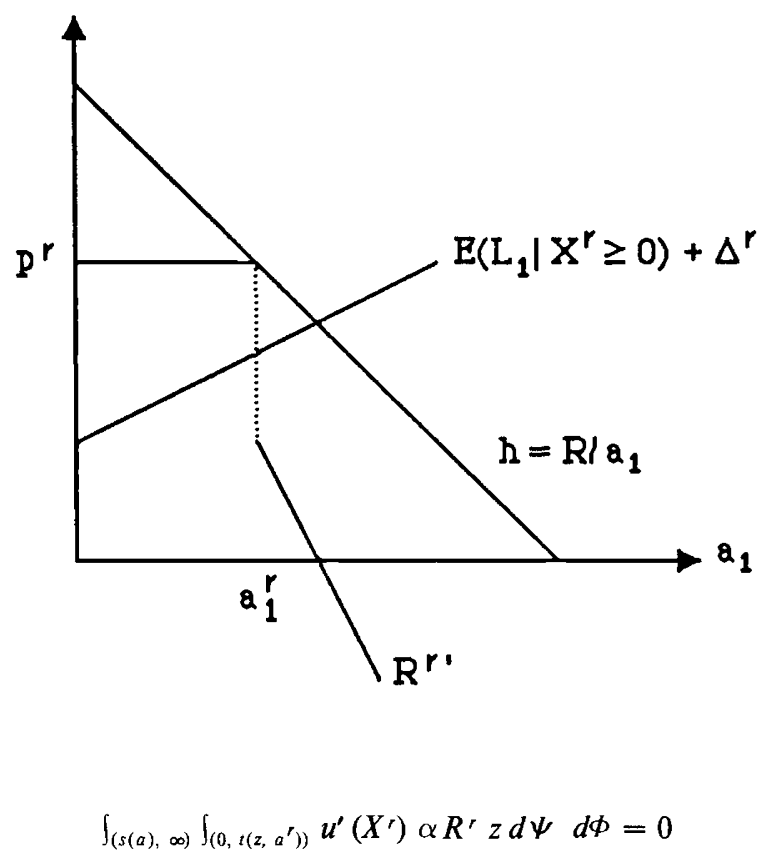

where

$$
X^{r}=X_{U}^{r}+X_{I}^{\prime}=R^{r} Z_{0}-L+a_{2} \alpha R^{r} Z=U^{r}+I^{r} .
$$


Let the function $G$ be defined by

$$
G\left(a_{1}^{r}, a_{2}\right)=\int_{(s(a), \infty)} \int_{\left(0, t\left(z, a^{r}\right)\right)} u^{\prime}\left(X^{r}\right) \alpha R^{r} z d \psi d \Phi .
$$

Since $G_{2}<0$, it follows that there exists a function $g$ such that $G\left(a_{1}^{r}, g\left(a_{1}^{r}\right)\right)=0$ and $g^{\prime}=-G_{1} / G_{2}$. Note that $g^{\prime}$ is greater or less than zero as $G_{1}$ is greater or less than zero.

$$
\begin{aligned}
G_{1}\left(a_{1}^{r}, a_{2}\right)= & \alpha R^{r^{\prime}} \int_{(s(a), \infty)} \int_{\left(0, t\left(z, a^{r}\right)\right)} u^{\prime}\left(X^{r}\right) z d \psi d \Phi \\
& +\alpha R^{r} R^{r^{\prime}} \int_{(s(a), \infty)} \int_{\left(0, t\left(z, a^{r}\right)\right)} u^{\prime \prime}\left(X^{r}\right) z\left[Z_{0}+a_{2} \alpha z\right] d \psi d \Phi \\
= & \alpha R^{r} R^{r^{\prime}} Z_{0} \int_{(s(a), \infty)} \int_{\left(0, t\left(z, a^{\prime}\right)\right)} u^{\prime \prime}\left(X^{r}\right) z d \psi d \Phi \\
& +a_{2} \alpha^{2} R^{r} R^{r^{\prime}} \int_{(s(a), \infty)} \int_{\left(0, t\left(z, a^{r}\right)\right)} u^{\prime \prime}\left(X^{r}\right) z^{2} d \psi d \Phi
\end{aligned}
$$

and

$$
G_{2}\left(a_{1}^{r}, a_{2}\right)=\int_{(s(a), \infty)} \int_{\left(0, t\left(z, a^{r}\right)\right)} u^{\prime \prime}\left(X^{r}\right)\left(\alpha R^{r}\right)^{2} z^{2} d \psi d \Phi<0
$$

Hence

$$
g^{\prime}\left(a_{1}^{r}\right)=-a_{2} R^{r^{\prime}} / R^{r}-\frac{R^{r^{\prime}} Z_{0} \int_{(s(a), \infty)} \int_{\left(0, t\left(z, a^{r}\right)\right)} u^{\prime \prime}\left(X^{r}\right) z d \psi d \Phi}{\alpha R^{r} \int_{(s(a), \infty)} \int_{\left(0, t\left(z, a^{r}\right)\right)} u^{\prime \prime}\left(X^{r}\right) z^{2} d \psi d \Phi}
$$

Notice that the sign of $g^{\prime}$ depends on the sign of the numerator in the second term on the RHS of (6), which may be difficult to determine. However, for the special case of constant absolute risk aversion, i.e., $r_{u}(X)=r$, for all $x$, one obtains

$$
\int_{(s(a), \infty)} \int_{\left(0, t\left(z, a^{r}\right)\right)} u^{\prime \prime}\left(X^{r}\right) z d \psi d \Phi=-r \int_{(s(a), \infty)} \int_{\left(0, t\left(z, a^{r}\right)\right)} u^{\prime}\left(X^{r}\right) z d \psi d \phi=0 .
$$

Hence, in this case $g^{\prime}=-d a_{2} / d a_{1}^{r}=-a_{2} R^{r^{\prime}} / R^{r}$. Therefore, if the regulated price is reduced (i.e., $a_{1}^{r}$ is increased) but still on the relatively elastic section of the demand curve, the optimal holding of the risky asset is reduced. Since $d R^{r}=R^{r^{\prime}} d a_{1}^{r}$, if follows that $d a_{2} / a_{2}=d R^{r} / R^{r}$. Recall that the dollar investment in the risky asset is $a_{2} \alpha R^{r}$; in this case, it follows that the dollar investment level will remain unchanged and as a result the mean and riskiness of the insurer's gain or loss on its stock market investment also remains unchanged. This result holds despite a positive probability of solvency.

A more general result is also possible. Since the work of Kihlstrom, Romer, and Williams, comparative static results have become relatively easy to obtain. Of course, in this case it requires the probability of insolvency to be zero. Then it is possible to show that the firm will increase its dollar investment in the risky asset. Consider the case in which the random variables $Y$ and $Z$ have compact supports. The the following analysis holds if the solvency set contains the cartesian product of the supports of $Y$ and $Z$, i.e., the probability of solvency is zero, as shown in Figure 6; the darkly shaded rectangle represents the cartesian product of the supports and the lightly shaded area is the solvency set. Now, it is possible to obtain a more general result by using the risk aversion measure introduced by Kihlstrom, Romer, and Williams [7]. Define the function $v$ as 


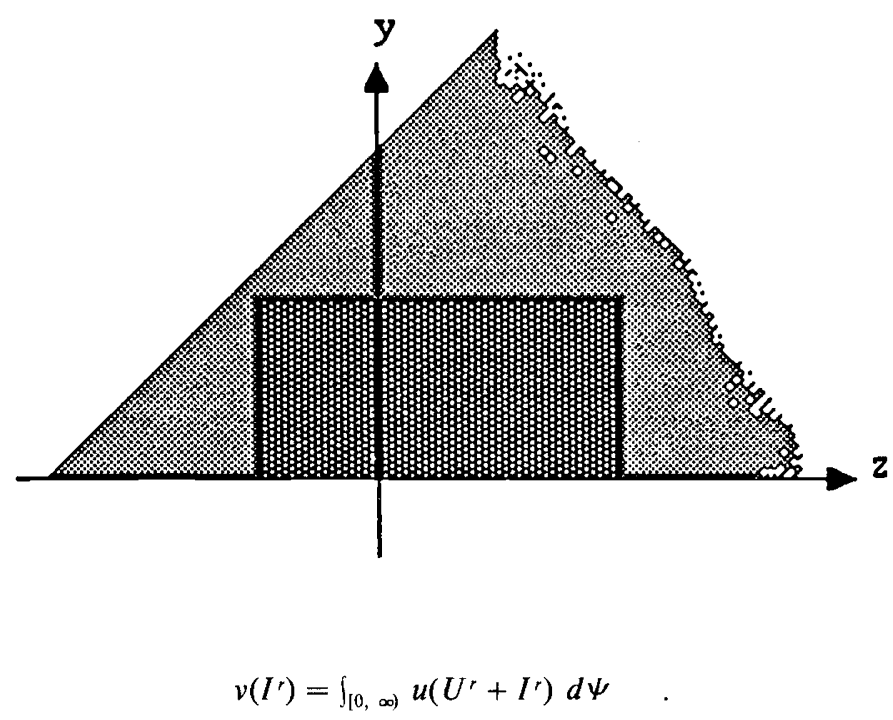

Then let

$$
r_{\nu}(I)=-v^{\prime \prime}(I) / v^{\prime}(I)
$$

be the measure of absolute risk aversion for the function $v$. It may be shown that if $r_{u}(X)$ is a decreasing function, then $r_{v}(I)$ is a decreasing function. This fact may be used to sign the integral

$$
\int_{(-\infty, \infty)} \int_{(0, \infty)} u^{\prime \prime}\left(U^{r}+I^{r}\right) z d \psi d \Phi=\int_{(-\infty, \infty)} v^{\prime \prime}\left(I^{r}\right) z d \Phi
$$

in (6). Given decreasing absolute risk aversion, it follows that

$$
r_{v}(I)=-v^{\prime \prime}(I) / v^{\prime}(I)>r_{v}(0), \text { for } z<0
$$

and

$$
r_{\nu}(I)=-v^{\prime \prime}(I) / v^{\prime}(I)<r_{\nu}(0), \text { for } z>0 .
$$

Thus,

$$
v^{\prime \prime}(I) z \geq-r_{\nu}(0) v^{\prime}(I) z
$$

for all $z$, and it follows that

$$
\int_{(-\infty, \infty)} v^{\prime \prime}\left(I^{r}\right) z d \Phi>-r_{\nu}(0) \int_{(-\infty, \infty)} v^{\prime}\left(I^{r}\right) z d \Phi=0
$$


Using this result in conjunction with (6), we may observe that decreasing absolute risk aversion yields

$$
d a_{2} / d R^{r}>-a_{2} / R^{r}
$$

or equivalently,

$$
d a_{2} / a_{2}+d R^{r} / R^{r}>0 .
$$

Hence, the percentage change in the firm's holding of risky stock is positive. This may be seen by recalling that the firm's dollar position in stock is $a_{2} \alpha R^{r}$, and so the percentage change is

$$
d \ln \left(a_{2} \alpha R^{r}\right)=\left(d a_{2} / a_{2}\right)+(d \alpha / \alpha)+\left(d R^{r} / R^{r}\right) .
$$

Unlike the constant absolute risk aversion case, the insurer will increase both the mean and the riskiness of $I$. The increase in the firm's position in the stock market is not necessarily due to a percentage increase in the proportional stock holding, $a_{2}$, but rather to an increase in revenue, $R^{r}$. This change in the firm's investment policy is reasonable, especially when it is noted that the effect of the price regulation on the firm's underwriting activity is an increase in the underwriting income. Then due to decreasing risk aversion, the insurer is willing to accept more risk in its investment activities. Hence, in response to the price reduction from regulation, the insurer with decreasing absolute risk aversion increases the riskiness of $I^{r}$ as the riskiness of $U^{r}$ increases, which seems to conflict with conventional wisdom in the insurance literature. However, a zero probability of insolvency is a strong, if not heroic, assumption not made in the insurance literature.

\subsection{Direct stock investment regulation}

Next, consider a regulatory scheme in which the firm's stock market investment is regulated directly, i.e., $a_{2} \leq a_{2}^{r}$. If this constraint is binding for the firm, then

$$
F_{2}\left(a_{1}, a_{2}^{r}\right)=\int_{\left(s\left(a^{r}\right), \infty\right)} \int_{(0, t(z, a))} u^{\prime}(X) \alpha R z d \psi d \Phi>0,
$$

where $s\left(a^{r}\right)=-Z_{0} / a_{2}^{r} \alpha$, and the firm selects $a_{2}^{r}$. Then the relation between $a_{1}$ and $a_{2}^{r}$ may be determined using the first order condition

$$
\int_{\left(s\left(a^{r}\right), \infty\right)} \int_{(0, t(z, a))} u^{\prime}(X)\left[R^{\prime} Z_{0}-L_{1}+a_{2}^{r} \alpha R^{\prime} z\right] d \psi d \Phi=0 .
$$

Let $K\left(a_{1}, a_{2}^{r}\right)$ be defined by the LHS of (8). Since $K_{1}<0$, it follows that there exists a function $k$ such that $K\left(k\left(a_{2}^{r}\right), a_{2}^{r}\right)=0$ and $k^{\prime}=-K_{2} / K_{1}$. Note that $k^{\prime}$ is positive or negative as $K_{2}$ is positive or negative.

$$
\begin{aligned}
K_{2}\left(a_{1}, a_{2}^{r}\right)= & \int_{\left(s\left(a^{\prime}\right), \infty\right)} \int_{(0, t(z, a))} u^{\prime}(X) \alpha R^{\prime} z d \psi d \Phi \\
& +\int_{\left(s\left(a^{r}\right), \infty\right)} \int_{(0, t(z, a))} u^{\prime \prime}(X) \alpha R z\left(R^{\prime} Z_{0}-L_{1}+a_{2}^{r} \alpha R^{\prime} z\right) d \psi d \Phi
\end{aligned}
$$

Recall that the first integral on the RHS of $(9)$ is positive. The sign of the second integral on the RHS of (9) is more of a problem. However, it is possible to sign $K_{2}\left(a_{1}, 0\right)$. 


$$
\begin{aligned}
K_{2}\left(a_{1}, 0\right)= & \alpha R^{\prime} \mu_{\mathrm{Z}} E\left\{u^{\prime}(U) \mid Y \leq h\left(a_{1}\right) Z_{0}\right\} P\left\{Y \leq h\left(a_{1}\right) Z_{0}\right\} \\
& \left.+\alpha R \mu_{\mathrm{Z}}\right\}_{\left(0, h\left(a_{1}\right) Z_{0}\right)} u^{\prime \prime}(U)\left[R^{\prime} Z_{0}-L_{1}\right] d \psi .
\end{aligned}
$$

Then if the firm's measure of absolute risk aversion, $r_{u}(x)$ is nonincreasing, it follows that

$$
\int_{\left(0, h\left(a_{1}\right) Z_{0}\right)} u^{\prime \prime}(U)\left[R^{\prime} Z_{0}-L_{1}\right] d \psi \geq 0
$$

Recall that the firm operates on the relatively elastic section of its demand curve, i.e., $R^{\prime}$ is positive, and the firm invests in the risky asset if and only if $\mu_{z}$ is positive. Therefore, given nonincreasing absolute risk aversion, $k^{\prime}(0)>0$, or equivalently, if the firm is initially constrained to make no stock purchases and then the constraint is relaxed, the firm will not only purchase risky stock, but will also decrease its price and increase the number of policies it writes. This result also follows from the observation that the probability of solvency initially increases with $a_{2}$, which means the increased probability of solvency increases the firm's expected payoff and allows it to optimally take on more risk.

\section{Summary}

A simplified financial model of the insurer under uncertainty was developed and used to examine its behavior under three regulatory constraints. The insurer is subject to two independent sources of risk: (1) the underwriting return on its insurance contracts and (2) the return on its investment portfolio.

It was shown that the insurer's risk premium is a function of both the insurer's underwriting and investment activities. The insurer was shown to select its investment in risky stock by equating the expected marginal return and the marginal risk premium on its investment portfolio. In similar fashion, the insurer was shown to select its level of underwriting activity so that the expected marginal return on underwriting equaled the expected marginal losses on its insurance portfolio plus a marginal risk premium for its underwriting activities. For a given optimal investment portfolio, the insurer was shown to select its level of underwriting such that its marginal revenue equaled its expected marginal losses plus a net marginal risk premium. The net marginal risk premium was shown to be a weighted difference between the marginal risk premiums on the firm's underwriting and investment activities. This result demonstrated the relationship between the insurer's pricing and investment policy. That is, the link between the insurer's investment and underwriting activities was shown to be the net marginal risk premium because it was the only factor which incorporated the investment choice in the model. If the probability of insolvency was zero and the insurer's utility function exhibited constant absolute risk aversion, it was shown that there was no relationship between the firm's investment and underwriting activities, i.e., underwriting and investment activities are separable.

After the model was developed, three regulatory schemes were examined in order to determine their impact on the behavior of the insurance firm. The first regulatory method examined involved the imposition of a constraint on the percentage of the insurer's underwriting revenue or policyholder-supplied funds that could be invested in risky stocks. Although one might expect the insurer's probability of insolvency to be reduced by such a regulation, it was shown that the insurer adjusted its investment choice so that its net 
marginal risk premium and its probability of insolvency remained the same. Thus, in all but one exceptional case, this type of regulation is not effective because the underwriting activity of the insurer is not altered.

Second, the effect of price regulation on the insurer was assessed. Here it was noted that the riskiness of the insurer's underwriting activity increased when its price was regulated. However, unlike what one might expect, it was shown that the insurer does not select a new investment policy characterized by less risk.

Finally, the impact of a direct regulatory constraint on the insurer's investment in risky stocks was examined. If the insurer is initially constrained to no investment in the stock market and then the constraint is relaxed, it was shown that the insurer not only purchase risky stock but also reduces the price of its insurance contracts.

\section{REFERENCES}

1. ARROW, K. J.: Essays in the Theory of Risk Bearing, North-Holland, Amsterdam, 1970.

2. BARON, D.: "Price uncertainty utility and industry equilibrium in pure competition", International Economic Review, 11 (October 1970), 463-480.

3. BROCKETT, P. L., and MACMINN, R. D.: "Notes on the Rothschild-Stiglitz equivalence result", unpublished paper, University of Texas, 1981.

4. CHAVAS, J.P.,: "On the theory of the competitive firm under uncertainty when initial wealth is random", Southern Economic Journal, 51 (January 1985), 818-827.

5. FRASER, R. W., and VAN NOORDEN, R. J.: "Extraction of an exhaustible resource: The effects on investment of several parameters being subject to uncertainty",Economic Record, 59(December 1983), 365-374.

6. FREIFELDER, L. R.: "Exponential utility thecry ratemaking: An alternative ratemaking approach", The Journal of Risk and Insurance, 46 (September 1979), 515-530.

7. KIHLSTROM, R., ROMER, D., and WILLIAMS, S.: "Risk aversion with random initial wealth", Econometrica, 49 (July 1981), 911-920.

8. LELAND, H.: "Theory of the firm facing uncertain demand", American Economic Review, 62 (June 1972), 278-291.

9. MACMINN, R. D.: "Forward markets, the stock market, and the theory of the firm", Working Paper, University of Texas, 1984.

10. MACMINN, R. D., and HOLTMANN, A.: "T echnological uncertainty and the theory of the firm", Southern Economic Journal, 50 (July 1983), 120-136.

11. McCABE, G.M., and WITT, R. C.: "Insurance pricing and regulation under uncertainty: A chanceconstrained approach", The Journal of Risk and Insurance, 47 (December 1980), 607-635.

12. PRATT, J. W.: "Risk aversion in the small and in the large", Econometrica, 32 (January-April 1964), 122-136.

13. ROTHSCHILD, M., and STIGLITZ, J. "Increasing risk I: A definition", Journal of Economic Theory, 2 (1970), 225-243. 
14. SANDMO, A.: "On the theory of the competitive firm under price uncertainty", American Economic Review, 61 (March 1971), 65-73.

15. SPELLMAN, L. J., WITT, R. C., and RENTZ, W. F.: "Investment income and non-life insurance pricing", The Journal of Risk and Insurance, 42 (December 1975), 567-577.

16. WITT, R. C.: "Pricing problems in automobile insurance: An economic analysis", The Journal of Risk and Insurance, 50 (March 1973), 75-93.

17. WITT, R. C.: "Pricing investment income, and underwriting risk: A stochastic view", The Journal of Risk and Insurance, 41 (March 1974), 109-133. 